\title{
The human neonatal gut microbiome: a brief review
}

\section{Emily C. Gritz and Vineet Bhandari*}

Division of Perinatal Medicine, Department of Pediatrics, Yale Child Health Research Center, Yale University School of Medicine, New Haven, CT, USA

\section{Edited by:}

Ira H. Gewolb, Michigan State University College of Human

Medicine, USA

\section{Reviewed by:}

Mark Martin Kadrofske, Michigan

State University College of Human

Medicine, USA

Pinaki Panigrahi, University of

Nebraska Medical Center, USA

Ira H. Gewolb, Michigan State

University College of Human

Medicine, USA

\section{*Correspondence:}

Vineet Bhandari, Division of Perinatal Medicine, Department of Pediatrics, Yale Child Health Research Center, Yale University School of Medicine, Room Number 219, P.O. Box 208081 464 Congress Avenue, New Haven, CT 06520, USA

e-mail: vineet.bhandari@yale.edu
The field of genomics has expanded into subspecialties such as metagenomics over the course of the last decade and a half. The development of massively parallel sequencing capabilities has allowed for increasingly detailed study of the genome of the human microbiome, the microbial super organ that resides symbiotically within the mucosal tissues and integumentary system of the human host. The gut microbiome, and particularly the study of its origins in neonates, has become subtopics of great interest within the field of genomics. This brief review seeks to summarize recent literature regarding the origins and establishment of the neonatal gut microbiome, beginning in utero, and how it is affected by neonatal nutritional status (breastfed versus formula fed) and gestational age (term versus preterm). We also explore the role of dysbiosis, a perturbation within the fragile ecosystem of the microbiome, and its role in the origin of select pathologic states, specifically, obesity and necrotizing enterocolitis (NEC) in preterm infants. We discuss the evidence supporting enteral pre- and pro-biotic supplementation of commensal organisms such as Bifidobacterium and Lactobacillus in the neonatal period, and their role in the prevention and amelioration of NEC in premature infants. Finally, we review directions to consider for further research to promote human health within this field.

Keywords: newborn, preterm, microbiota, probiotics, dysbiosis

\section{INTRODUCTION}

The evolution of the field of genomics, spurred largely by the Human Genome Project, has given rise to metagenomics, or "the application of modern genomics techniques to the study of communities of microbial organisms directly in their natural environments" (1). This burgeoning area of study has resulted in significant advances in whole-genome analysis techniques that have greatly facilitated the study of the human microbiome.

The human microbiome is a microbial community best described as "the sum of all microbial life living in or on the human body" (2). It is an entity that has wide-reaching metabolic, nutritional, and immunological effects on the host, and as such has generated a great deal of interest within the biomedical research community. The microbiome evolves within a healthy host from birth to death, constantly fine-tuning it to maintain a homeostatic balance with the host's immune system. Continued evolution of the human microbiome after birth is governed by host factors such as both the adaptive and innate immune system, as well as external factors such as diet, medication and toxin exposure, and illness (3, 4). Of particular interest is the study of the gut microbiome, its evolution beginning in utero and across the lifespan, its effect on promotion of health, and its role in the development of disease.

The purpose of this brief review is to introduce the reader to the concept of the human microbiome and to summarize recent literature specifically regarding the neonatal gut microbiome, from its establishment at birth through its evolution during early infancy. We review differences in microbial colonization and immune function of the intestinal tract in healthy full-term newborns compared with their preterm very low birth weight (VLBW) (birth weight $<1500 \mathrm{~g}$ ) counterparts and the implications for development of disease when the microbiome is disrupted (dysbiosis). Finally, we describe the role of probiotic use as a potential factor involved in governing development of a "healthy" gut microbiota and discuss areas of further research warranted to deepen our understanding of this complex ecosystem and its role in human health and disease.

\section{ESTABLISHMENT AND EVOLUTION OF THE NEONATAL GUT MICROBIOME}

The first, and most important, contribution to the genesis of the microbiome is vertical transmission of maternal microbiota. Colonization of mucosa in the digestive, respiratory, urogenital tracts, as well as the skin begins at, or perhaps even before, the time of birth when a newborn is exposed to a mother's microbiota. It was previously thought that the in utero environment was largely sterile and that a fetus was not colonized with bacteria until the time of birth. Recent studies suggest the presence of a microbiome within the placenta as well as fetal meconium, suggesting that the colonization process begins well before delivery. Aagaard et al. have recently characterized a placental microbiome profile, composed of non-pathogenic commensal microbiota from the Firmicutes, Tenericutes, Proteobacteria, Bacteroidetes, and Fusobacteria phyla which, interestingly, shares some similarities with the human oral microbiome (5). They observed that in the first week of life the fullterm neonatal gut microbiome is largely colonized by members of the Actinobacteria, Proteobacteria, Bacteroidetes, and, much less, Firmicutes phyla (Figure 1) $(5,6)$. This is contrasted with the previously described finding that neonates weighing $<1200 \mathrm{~g}$ have a gut microbiome dominated by members of both Firmicutes and Tenericutes phyla $(5,7,8)$. This evidence of early colonization 


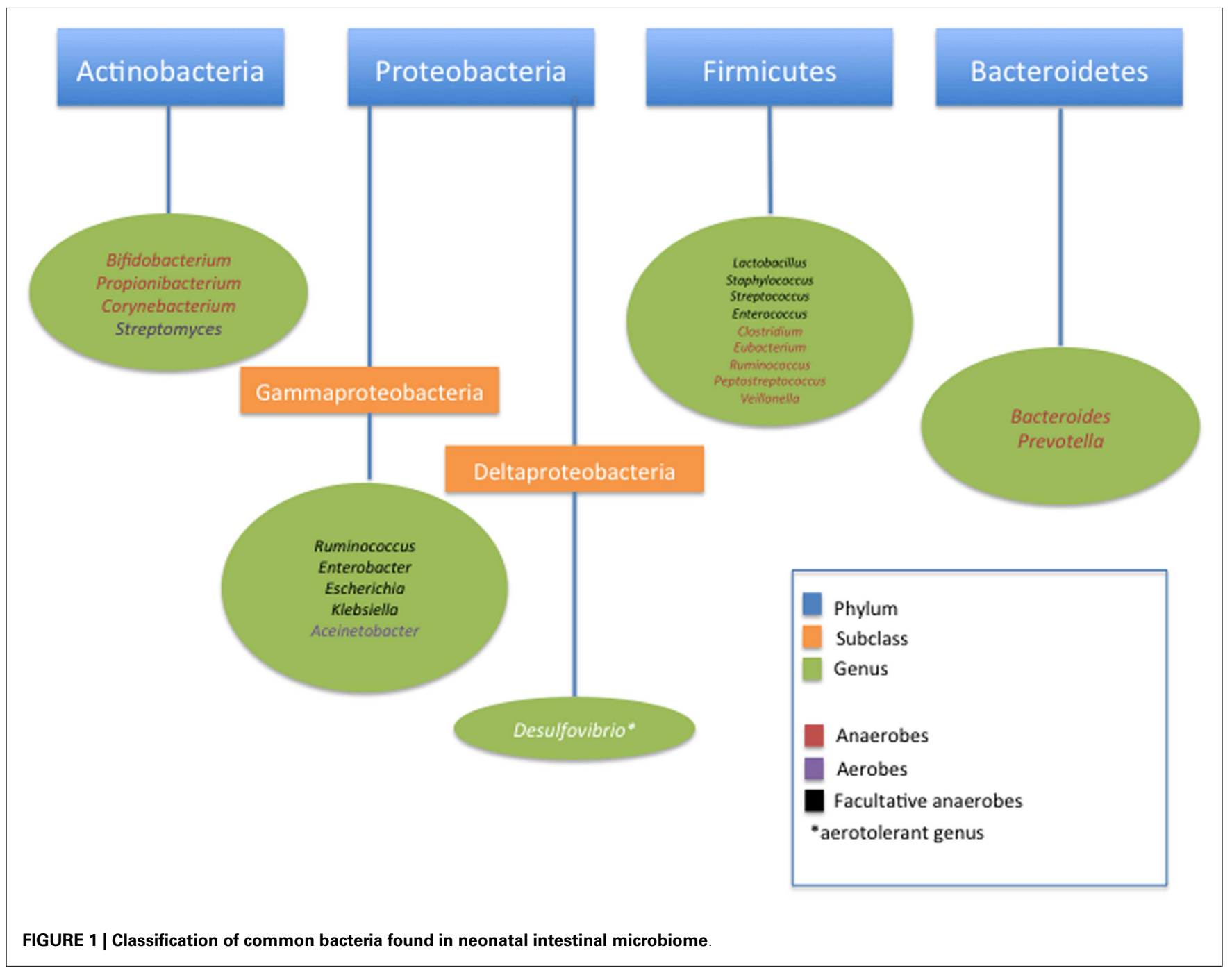

of the neonatal gut microbiome so close to the time of birth suggests that there may be exposure to an antenatal source of commensal bacteria, such as the placenta, and this seeding may vary by length of gestation (5). It is well known that as fetuses become more neurologically mature, they begin to swallow large amounts of amniotic fluid, particularly during the third trimester of pregnancy. If the uterine environment is colonized with its own microbiota, as is suggested in recent studies, then the fetal gut may in turn become colonized by these organisms. Recent studies suggesting that meconium is not sterile support this theory (9). Ardisonne et al. evaluated meconium samples from neonates and found that bacterial species in meconium were shared with organisms found in the amniotic fluid (10).

As such, the gastrointestinal (GI) tract has the greatest diversity and abundance of microbes and evidence is mounting that it becomes colonized antenatally. Approximately 100 trillion organisms - which is 10 times the total number of cells in the human body - typically comprise the gut microbiota and the majority of these populate the distal ileum and colon. More than $99 \%$ of the gut microbiota is anaerobes $(6,11)$. Interestingly, each individual's microbiome is populated by only $15 \%$ of the 1000 plus species of intestinal bacteria already described, leading to significant interindividual variability of the microbiome $(4,12)$. Eckburg et al. examined 13,355 prokaryotic ribosomal RNA gene sequences from intestinal mucosal tissue samples and fecal samples of healthy adult subjects and observed that of 395 bacterial phylotypes identified, 244 were novel, and $80 \%$ represented sequences from species that have not been cultivated (13).

It is easy to conceptualize then that the collective genome of the intestinal microbiota is $>100$ times the number of genes in the human genome; as such, there are a significant potential number of commensal antigens for the host immune system to encounter and to respond. This exceeds the number of self and pathogen-based antigens a human will encounter in their lifetime (12).

Infants born via vaginal delivery have intestinal colonization reflective of maternal vaginal flora such as Lactobacillus and Prevotella species. Infants born via Cesarean delivery are colonized by epidermal rather than vaginal species, such as Clostridium, Staphylococcus, Propionobacterium, and Corynebacterium and they have a deficiency of anaerobes with lower numbers of Bacteroides and 
Bifidobacterium when compared to vaginally born infants (1418). Thus, the mode of delivery appears to have an influence on the diversity and function of an infant's microbiota, which can persists for months and, perhaps longer, after birth. Jakobsson et al. demonstrated that full-term infants delivered via Cesarean section lacked or displayed delayed gut colonization by members of the Bacteroidetes phylum by up to 1 year, with an overall lower total microbial diversity (19). Other studies have also shown persistent differences in intestinal microbial colonization between Cesareandelivered and vaginally delivered children as far as 7 years of age (20).

Further development of the neonatal gut microbiome after birth, regardless of mode of delivery is governed by interaction between the microbiota and the host's immune system. The progression of how this evolves remains incompletely characterized and many questions remain surrounding the true origins of the microbes that colonize the neonatal gut and what factors underlie inter-infant differences in gut microbiota, Palmer et al. evaluated stool samples of 14 healthy full-term infants using rDNA microarray technology to define their gut microbial profiles over the course of their first year of life and found that while at a phylum level diversity of the analyzed samples was mostly limited to Flexibacter-Cytophaga-Bacteroides, Proteobacteria, and Firmicutes and Actinobacteria; there was a remarkable level of inter-individual variation from baby to baby over the course of the study (21). They noted an overall earlier appearance of aerobes such as Staphylococcus, Streptococcus, and Enterobacteria; a later appearance of anaerobes such as Eubacteria and Clostridium, and variable timing of the emergence of Bacteroides, which ultimately established a presence in all babies by age 1 year. Transient colonization was noted at varying time points by other organisms including Prevotella, Acinetobacter, Desulfovibrio, Veillonella, and Clostridium perfringens (21). In contrast, a 2012 study by Turroni et al. demonstrated Bifidobacteria species as a predominant component of the term infant gut microbiota, challenging the notion that the infant gut contains low numbers of Bifidobacterium (22). The differences seen between these studies highlights the need for cautious further investigation to best characterize the infant gut microbiome. Nevertheless, gut colonization patterns established within the first week of life are thought to have effects on the composition of the individual's future gut microbiota via a variety of factors $(17,19,23,24)$. The term infant's gut microbiome undergoes rapid maturation over the first year of age and is securely established in an adult form by 3 years of age. An individual's ultimate adult gut microbiome profile is likely governed by an elucidated interplay between initial colonizing microbiota, genes, normal gut development, diet, and environment $(14,21,25,26)$.

Once established, the intestinal microbiome engages in a symbiotic relationship with its host. The neonatal immune system will rapidly mature secondary to influence of microbiota, diet, exposure to new microbes, xenobiotics, and other environmental exposures (12). The organisms that comprise the microbiota benefit from the warm, nutrient-rich environment afforded by the gut. This allows for optimum growth within a stable ecosystem. The human, in turn, benefits from activities of the microbiota that primarily allow for an increased digestive capacity and an ability to harvest nutrients from food. Weaning from breast milk or formula and introducing solid foods causes a shift in composition of the neonatal gut microbiome and leads to increased counts of Bacteroides, Clostridium, and anaerobic species of Streptococcus but decreased numbers of Bifidobacterium. This shift in bacterial makeup leads to expression of bacterial genes that are involved both in degradation of xenobiotic compounds, vitamin biosynthesis, and production of other metabolites such as butyrate and acetate $(21,25,27,28)$. In addition to these pro-nutrient effects, the intestinal microbiome can limit nutrient resources available to pathogens, specifically by out-competing them for metabolic resources and for physical space $(12,27)$. Gut microbiota also aid in development of barrier function, integrity, and systemic immune function. This includes formation of a tolerant state between gut organisms and the immune system and is thought to affect tight junction structure and function $(3,29)$. Generation of pro-inflammatory or anti-inflammatory responses as a result of exposure to bacteria include activation or deactivation of toll like receptors, T-lymphocyte activation, and triggering secretion of pro- and anti-inflammatory interleukins and cytokines, as well as activation of B-cells within the mesenteric lymph node system $(3,25)$ - the scope of which is beyond this present review. Overall, these arms of the innate and adaptive immune system interact with the microbiota to establish normal digestive capabilities, gut motility, immune tolerance to foods and certain microbial antigens, and protection against pathogens (25). The exact role of the neonatal gut microbiome in the development and maturation of the infant immune system, as well as the influence of the neonatal immune system on governance of the fledgling gut microbiome is still poorly understood from a mechanistic standpoint and continues to be a growing area for further research (27).

\section{THE ROLE OF NUTRITION IN DEVELOPMENT OF THE FULL-TERM NEONATAL GUT MICROBIOME}

Nutrition, be it breast milk or formula, has been demonstrated to play a major role in early colonization patterns of the neonatal gut microbiota. Healthy, full-term breastfed infants receive a mix of nutrients, bacteria, and antimicrobial proteins, such as carbohydrates, fatty acids, and lactoferrin along with secretory IgA (sIgA) from their mother's milk that will affect the milieu within which their own microbiota will develop (27). Oligosaccharides, glycoconjugates, and natural components of human milk are also thought to prevent the attack of enteropathogens and stimulate growth of Bifidobacterium (4, 30, 31). These human milk oligosaccharides are known to directly interact with the surface of pathogenic bacteria, and various oligosaccharides in milk are believed to inhibit the binding of pathogens and toxins to host cell receptors (32). Other constituents of human milk, such as interleukin-10, epidermal growth factor, transforming growth factor- $\beta 1$, and erythropoietin, can represent important mediators in the inflammatory response against bacterial pathogens within the gut (4).

Live bacteria are also found in human milk, including Staphylococcus, Streptococcus, Bifidobacterium, and Lactobacillus (33). Several associated factors influence the dynamic composition of the breast milk microbiota, including maternal health and mode of delivery (34). At least some of the bacteria present in the maternal gut is thought to reach the mammary gland through 
an endogenous route, the so-called enteromammary pathway and likely contributes to the bacterial composition of breast milk (17). The composition of breast milk bacteria becomes increasingly less diverse, beginning with typical skin- and enteric-type organisms in colostrum to less diverse flora with greater infant oral and skin microbiota as lactation progresses (35). Non-digestible carbohydrates found in breast milk ferment in the colon and promote further growth of probiotic Bifidobacterium and Bacteroides species (27). Interestingly, it has also been noted that during lactation, the cells of the maternal intestinal lymphoid tissue travel via the lymphatic and vascular circulations to the breast, facilitating the transfer of maternal intestinal and mammary skin microbiota to the breast-fed newborn $(4,36)$.

Formula-fed infants are exposed to a different array of carbohydrates, bacteria, and nutrients, which leads to different colonization patterns and immunomodulatory effects on their developing gut microbiota. In contrast to human milk oligosaccharides as mentioned earlier in this section, oligosaccharides currently added to infant formula are structurally different from those naturally found in human milk and, therefore, are unlikely to mimic some of the structure-specific effects on the gut that are seen in breastfed neonates (32). It has been demonstrated that term breastfed infants have a gut microbiota dominated by species of Bifidobacterium but decreased Enterobacteria. Formula-fed counterparts, regardless of milk-based or soy-based formula composition, have a gut microbiota comprising a more diverse array of bacteria including Escherichia coli, Clostridium difficile, Bacteroides, Prevotella, and Lactobacillus (14-16, 27, 37-40) (Table 1). Interestingly, even relatively small amounts of formula supplementation of breast-fed infants will result in shifts from a breast-fed to a formula-fed pattern $(41,42)$. A 2011 study by Hascoet et al. demonstrated, however, that infants, who received a formula low in phosphate and protein, comprise mainly whey protein in an attempt to provide a composition closer to human milk, developed a stool microbiota profile similar in Bifidobacteria composition to that for breast-fed infants (43). This suggests that even in infants not receiving exclusive breast milk, a breast-fed gut microbiota could be achieved, in part at least, by supplementing with a type of formula having a composition similar to breast milk.

In breast-fed infants, transmission of sIgA from the mother is reflective of her own microbiota and confers a protective effect

\section{Table 1 | Major differences in neonatal gut colonization by type of feeding.}

Breast fed

Bifidobacteria ${ }^{a}$

Enterobacteria species

\section{Formula fed}

Bifidobacteria species

Escherichia coli

Clostridium difficile

Bacteroides species

Prevotella species

Lactobacillus species

${ }^{a}$ Breast-fed infants have more colonization with Bifidobacteria species than their formula-fed counterparts. against pathogens that could lead to dysbiosis, the disruption of a healthy, functional infant microbiome. sIgA is also thought to shield the neonatal immune system from its own microbiota while host defenses are maturing. The purported mechanisms for this are binding of microbial antigens by $\operatorname{sgA}$ and activation of the host's innate immune system in a more "tolerogenic" mode upon antigen exposure. This promotes formation of regulatory immune networks that further govern development and function of the gut microbiome (12).

This difference in colonization and transmission of immunemodulating factors between breast and formula-fed infants may have far reaching effects over the course of a human's life as it may impact disease risk. The gut microbiota's metabolic activity, specifically its ability to extract nutrients from food consumed by its host, may have a variable effect, depending on species diversity and composition, on an infant's ability to store and utilize energy efficiently (14). An increasingly investigated avenue is the relationship between alterations in the gut microbiome and its possible involvement in the development of disease later in life. A prime example of this is the obesity epidemic, which may begin as early as the perinatal period. While this epidemic is thought to be primarily due to excessive consumption of carbohydrates and fats coupled with decreased physical activity, childhood obesity has been, "in part, attributed to the fetus exposure to unfavorable conditions (e.g., nutritional and hormonal dysfunctions) in the uterine life, which can then exert a strong impact on the subsequent development, structure, and function of the child organism" $(4,44)$. This phenomenon, which can extend to perinatal and postnatal age, is known as disease programing during the development phase $(4,45)$.

As previously noted, the gut microbiota serves a critical metabolic function for its host. In particular, it enables digestion of otherwise indigestible carbohydrates and triggers activation of lipoprotein lipase. This leads to glucose absorption and storage of fatty acids and thus to excessive weight gain. Increased numbers of Firmicutes and decreased Bacteroidetes in the gut microbiota have also been shown in experimental animal models to predispose toward excess energy storage and obesity $(46,47)$. Production of metabolites such as short chain fatty acids such as butyrate and acetate by early commensal gut microbiota may play a role in epigenetic alteration of gut epithelium and immune function that predispose to diseases like obesity $(25,48)$. Kalliomaki et al. demonstrated increased Bifidobacterium in fecal samples during the first year of life in children who remained normal weight at 7 years of age when compared to children who became overweight (46). Luoto et al. later reinforced this finding by demonstrating in a 2011 longitudinal study of 30 obese children that obese subjects had lower levels of Bifidobacterium as infants when compared to normal weight counterparts (49). VLBW infants are paradoxically at increased risk for development of obesity later in life possibly due to metabolic programing that predisposes toward energy storage even when nutrients are not in short supply. An alternative hypothesis, which could explain this predisposition toward obesity in this population centers around altered nutrient processing and utilization and immune regulation, has a function of altered gut microbiota (25). To date, little research has been done to evaluate the effect of composition of the neonatal gut microbiota, term or 
preterm, its relationship to early nutritional status, and its effect on later development of obesity and other pro-inflammatory disease states. Given obesity's long-reaching effects across the lifespan, seeking to further understand its origins and metabolic underpinnings, perhaps beginning as early as the neonatal period, remains an important focus of continued investigation.

\section{THE PRETERM GUT MICROBIOME}

Preterm infants, particularly VLBW infants, are at a disadvantage when it comes to development of a healthy microbiome. Factors contributing to this are not limited to their gut immaturity, and also include preterm rupture of membranes, maternal infection, increased incidence of Cesarean delivery, perinatal and postnatal broad-spectrum antibiotic exposure as well as exposure to other gut-modifying medications such as $\mathrm{H} 2$ blockers, altered gut motility, periods of fasting, intensive care infection control standards and selection for resistant microbes, and decreased exposure to human milk $(17,25,29,50)$. Given these factors, it seems likely, and has indeed been shown to be true that a preterm infant's gut microbiota has reduced microbial diversity coupled with an increase in colonization with pathogenic organisms $(17,51)$. Additionally, the preterm gut microbiome is less stable compared to that of term counterparts and is also thought to be delayed in transition to an adult colonization pattern $(3,14,25,29)$. Arboleya et al. demonstrated this by comparing full-term breastfed vaginally delivered infants with preterm infants with regard to differences in representation of 18 microbial groups within gut flora. They demonstrated that when compared with full-term infants, preterm infants showed increased populations of facultative anaerobes such as Enterococcus, Enterobacter, and Lactobacillus, increased numbers of Staphylococcus, and decreased numbers of anaerobes like Bifidobacterium, Bacteroides, and Atopobium (3, 29, 52). A 2007 study by Butel et al. found that healthy full-term breastfed infants are colonized by Bifidobacterium by day 7 of life, whereas preterm infants are not. Interestingly, they also suggest that there may be gestational age thresholds for colonization with certain microbes - 33 weeks appears to be the milestone for appearance of Bifidobacterium species, the organism most commonly implicated in development and maintenance of a healthy gut microbiome (53). Very recently, LaRosa et al. used 16s rRNA gene pyrosequencing to show a reproducible longitudinal succession of bacterial classes from Bacilli to Gammaproteobacteria to Clostridia in 58 VLBW infants born at 23-33 weeks gestational age in a single neonatal intensive care unit (NICU). They found that this evolution was marked by periods of "abrupt population changes" that ultimately achieve a common endpoint wherein by 33-36 weeks postconceptional age, study infants consistently had gut microbiota predominantly colonized by anaerobes, particularly Clostridia, which approached levels of older individuals. Of note, mode of delivery, antibiotic exposure, mode of feeding, and age of infants at time of sampling only affected the rate of progression toward an anaerobic-dominated microbiota in the study infants, and not the sequence to achieve it (54). A 2013 study of longitudinal development of the preterm gut microbiome in twins also demonstrates that they share similar gut microbiome development even within the complex, multiexposure environment of a NICU suggesting that in preterm infants, development of the gut microbiome may also be influenced by genetics (51). While the evolution of the term infant gut microbiome has been somewhat characterized, to date, there are still few prospective studies of the evolution of the preterm, VLBW gut microbiome to assess if there is a characteristic patterned succession and time course of microbial colonization for this group from birth through early childhood.

In addition to altered microbial diversity as described above, premature infants are both qualitatively and quantitatively immunodeficient, owing to their underdeveloped immune systems. They have suboptimal gut epithelial cell barrier function at baseline, predisposing them to invasion by pathogens that in turn can trigger exaggerated inflammatory responses by their stilldeveloping immune system that may lead to disease processes such as necrotizing enterocolitis (NEC) $(16,55)$. This immune dysfunction, coupled with low diversity of gut microbiota and possibly an overall predominance of pathogenic bacteria within the preterm intestinal microbiome has been noted in at-risk preterm neonates with life threatening Enterobacter and coagulase negative Staphylococcus sepsis, and is a prime example of dysbiosis $(14,56,57)$.

\section{DYSBIOSIS}

Even after the microbiome is well established in healthy infants, dysbiosis, or shifts in microbial composition or diversity, can occur in the setting of dietary changes, antibiotic exposure, or infection. Dysbiotic conditions can favor invasion and growth of pathogenic species and can disrupt the finely tuned regulatory circuits of the immune system that maintain a system of pro- and antiinflammatory checks and balances. The neonatal microbiome, in healthy full-term infants and especially in preterm infants given its dynamic nature, is fragile and impressionable. As such, the microbiome is extremely susceptible to external influences that can dramatically affect the short- and long-term health of the host. The development of NEC in the preterm population is a multifactorial, devastating, and as yet poorly understood disease process. A link between NEC and a microbial etiology has been recognized for decades and has been corroborated by outbreaks in NICUs, the presence of pneumatosis intestinalis as a likely byproduct of bacterial fermentation, and the often concomitant presence of bacteremia (58). As such, NEC is increasingly thought to be, at least in part, related to a perturbation of intestinal immune homeostasis, and a generalized disturbance of normal colonization patterns within the developing gut, rather than growth of a single pathogen $(59,60)$. The advent of a variety of techniques for metagenomic analysis of the developing human gut microbiome has given way to studies investigating whether there is a signature microbial pattern that predisposes to or heralds the onset of NEC. As summarized by Berrington et al., recent analyses of microbiomic data from preterm infants with NEC show great variability in proposed dysbiotic growth patterns (3). Some studies implicate increased Proteobacteria and decreased Firmicutes in the development of NEC (61), while others note more than one pattern of dysbiosis within a given neonatal cohort. Morrow et al. noted both Firmicute dominant and Proteobacteria dominant patterns within their cohort of preterm infants, the former being associated with earlier presentation of NEC, the latter with later 
presentation (62). Alternatively, other groups have found no differences in microbiota between NEC-affected patients and healthy controls (63).

\section{THE ROLE OF PRE- AND PRO-BIOTICS IN DEVELOPMENT OF THE NEONATAL GUT MICROBIOME}

Given the relative instability and impressionability of the developing gut microbiome in early life, coupled with its purported disease prediction, detection, and treatment benefits, it seems logical to explore avenues within which evolution and maintenance of a healthy gut milieu can be promoted. One such intervention that has gained overwhelming popularity over the last two decades, but that remains a controversial topic, is the use of pre- and probiotics. Given that an infant's health and well-being are tightly linked to the development of the intestine and its digestive and immune capacities, it would seem logical that manipulation of the microbiota with the use of pre- and/or pro-biotic nutritional supplementation at an early stage could have a high and long-lasting impact (11).

Prebiotics are "non-digestible food ingredients that selectively stimulate the growth or activity of anaerobic/microaerophilic flora (Bifidobacterium/Lactobacillus) in the colon of mammals" (55). Some studies also suggest that in addition to promoting growth of commensal organisms like Bifidobacterium and Lactobacillus, prebiotics may also improve intestinal motility and gastric emptying (64-66). These sugars are present in several food sources, including breast milk and commercially available infant formulas. Lactoferrin is a natural component of human milk with antimicrobial, immunostimulatory, and immunomodulatory properties and has been shown to promote a gut environment in neonates that predisposes toward colonization with favorable bacterial such as Bifidobacterium and Lactobacillus species (67). Mastromarino et al. recently demonstrated that early high levels of fecal lactoferrin in neonates may contribute to the immunologic maturation and overall health of the newborn by promoting colonization with Bifidobacterium and Lactobacillus species, particularly in preterm infants (67). Inulin, lactulose, and short chain fructooligosaccharides (FOS) and galacto-oligosaccharides (GOS) are several other well-studied prebiotics in humans, but their use, efficacy, and safety in the neonatal population, particularly the preterm neonatal population, is not well studied (55).

Probiotics are live microorganisms that when administered in adequate amounts, ideally confer a health benefit on the host - as defined by the World Health Organization (WHO). Probiotic supplementation in the preterm neonatal population is purported to promote acquisition of normal commensal gut flora in these compromised hosts and to confer a protective effect against dysbiotic conditions such as NEC.

Several recent clinical trials and meta-analyses on this subject suggest that probiotic administration for NEC prevention is overall thought to be safe and effective (68). It is important to note, however, that the significant degree of heterogeneity among studies included in these meta-analyses renders conclusions about the safety and efficacy of probiotics in the vulnerable preterm population up for debate $(55,69)$. To date, virtually all trials use combinations of different probiotics. Common probiotic preparations given to neonates include Lactobacillus and Bifidobacterium.
Probiotic preparations that recently have been studied in the neonatal population are summarized in Table 2. Of note, of the 12 trials described in the table, 4 of them cite no difference in NEC prevention between treatment and placebo groups. Further examination of Table 2 highlights a notable degree of study to study variability in terms of inclusion criteria, type, and dose of probiotic administered. In addition, in one study, a fungal species (Saccharomyces) is used as a probiotic. This diversity in design and execution of clinical studies of probiotics in neonates is also evident in the recent meta-analyses by Deshpande et al., and Wang et al., a systematic review by Mihatsch et al. and a 2014 Cochrane review (69-72). These factors may, in part, underlie the variability of outcomes related to NEC prevention. Janvier et al. has commented that across recent trials "subgroup analyses demonstrate little difference in the effects of probiotics between those containing lactobacilli, those containing just Bifidobacteria, and those containing a mixture, although there are trends suggesting that a mixture of different organisms may be more effective than a single species," but this continues to require further study $(73,74)$.

Another important consideration in evaluating whether or not the use of probiotics in this population is warranted is the effective dose and duration of treatment. In order to produce health effects, probiotic organisms need to be able to survive within the GI tract and persist at high levels within the intestine (86), but the minimum effective dose at which this can be achieved remains to be determined. Historically, the ability to reliably determine what organisms colonize the intestinal tract has been limited by use of plate culture methods that only allow identification of a limited number of organisms within the vast microbial population of the gut (87). The advent of highly sensitive techniques such as quantitative PCR (qPCR) enables detection and quantification of as little as a single copy of target DNA. This, coupled with improved computer-based comparative metagenomic techniques, allows for better characterization of the organisms that colonize and comprise the intestinal microbiome (88).

A 2003 study by DeChamps et al. evaluated the colonization ability of Lactobacillus rhamnosus Lcr 35 at doses of $10^{8}, 10^{10}$, $10^{12} \mathrm{CFU} /$ day over a 3 -week period in 12 healthy adults and found no relation between the average number of cultured Lactobacillus Lcr 35 CFU in feces and doses ingested by study subjects (86). They demonstrated that following a 3 -week post-treatment period wherein no probiotics were administered to subjects, the CFU levels of Lactobacillus in fecal samples were slightly decreased, albeit similar to levels observed immediately following probiotic treatment (86). A culture-based 2008 study by Panigrahi et al. evaluated healthy newborns $>35$ weeks gestation who were given a synbiotic (Lactobacillus plantarum and fructooligosaccharide) for 7 days and found that the synbiotic produced rapid colonization of the infant GI tract (within 3 days of administration) and infants remained colonized, at decreasing rates, for several months after therapy was stopped (89). Costa et al. evaluated 61 healthy adults who received daily $L$. plantarum for differing periods of time. L. plantarum levels were monitored over time using $\mathrm{qPCR}$. They noted a discrepancy between the daily intake of Lactobacillus $\left(2 \times 10^{11}\right.$ cells/dose $)$ and levels detected in feces $\left(10^{4}\right.$ cells/g), but noted that they were unable to account for the distribution or fate of bacteria within the GI tract following ingestion. Interestingly, 


\begin{tabular}{|c|c|c|c|c|c|c|c|}
\hline Reference & Year & $\begin{array}{l}\text { Study } \\
\text { type }\end{array}$ & $\begin{array}{l}\text { Study } \\
\text { size }\end{array}$ & Inclusion criteria & Probiotic species studied $^{a}$ & Daily dose & Outcomes \\
\hline Janvier et al. (73) & 2014 & Cohort & 294 & $<32$ weeks Gestational age & $\begin{array}{l}\text { Bifidobacterium breve } \\
\text { Bifidobacterium bifidum } \\
\text { Bifidobacterium infantis } \\
\text { Bifidobacterium longum } \\
\text { Lactobacillus rhamnosus }\end{array}$ & $2 \times 10^{9} \mathrm{CFU}$ & $\begin{array}{l}\text { Significantly decreased incidence of NEC in subjects receiving probiotics } \\
\text { No effect on in incidence of death } \\
\text { No effect on rates of healthcare associated infection }\end{array}$ \\
\hline Oncel et al. (75) & 2014 & $\mathrm{RCT}$ & 424 & $<32$ weeks Gestational age & Lactobacillus reuteri & $1 \times 10^{8} \mathrm{CFU}$ & $\begin{array}{l}\text { No effect of probiotic therapy on overall rates of NEC and/or death } \\
\text { Noted decreased feeding intolerance in infants receiving probiotic therapy }\end{array}$ \\
\hline Jacobs et al. (76) & 2013 & $\mathrm{RCT}$ & 1099 & $<32$ weeks Gestational age & $\begin{array}{l}\text { Bifidobacterium infantis } \\
\text { Bifidobacterium lactis } \\
\text { Streptococcus thermophilus }\end{array}$ & $1 \times 10^{9} \mathrm{CFU}$ each & $\begin{array}{l}\text { Significant reduction in rates of NEC (Bell stage } \geq 2 \text { ) } \\
\text { No effect on rates of late-onset sepsis } \\
\text { No effect on overall neonatal mortality }\end{array}$ \\
\hline Serce et al. (77) & 2013 & $\mathrm{RCT}$ & 208 & $\begin{array}{l}<32 \text { weeks Gestational age } \\
\text { Birth weight }<1500 \mathrm{~g}\end{array}$ & Saccharomyces boulardii & $1 \times 10^{9} \mathrm{CFU}$ & No effect on incidence of NEC or sepsis \\
\hline $\begin{array}{l}\text { Fernandez- } \\
\text { Carrocera et al. } \\
\text { (78) }\end{array}$ & 2013 & $\mathrm{RCT}$ & 150 & Preterm infants & $\begin{array}{l}\text { Bifidobacterium infantis } \\
\text { Lactobacillus rhamnosus } \\
\text { Lactobacillus acidophilus } \\
\text { Lactobacillus casei } \\
\text { Lactobacillus plantarum } \\
\text { Streptococcus thermophilus }\end{array}$ & $\begin{array}{l}2.76 \times 10^{7} \mathrm{CFU} \\
4.4 \times 10^{8} \mathrm{CFU} \\
1 \times 10^{9} \mathrm{CFU} \\
1 \times 10^{9} \mathrm{CFU} \\
1.76 \times 10^{8} \mathrm{CFU} \\
6.6 \times 10^{5} \mathrm{CFU}\end{array}$ & $\begin{array}{l}\text { No differences were detected in terms of NEC risk reduction } \\
\text { Decreased frequency of NEC } \\
\text { Significantly decreased combined risk of NEC or death in infants receiving } \\
\text { probiotic therapy }\end{array}$ \\
\hline Rojas et al. (79) & 2012 & $\mathrm{RCT}$ & 770 & Birth weight $<2000 \mathrm{~g}$ & Lactobacillus reuteri & $1 \times 10^{8} \mathrm{CFU}$ & $\begin{array}{l}40 \% \text { Overall decrease in NEC cases, but not significant } \\
\text { Decreased feeding intolerance in infants receiving probiotic therapy }\end{array}$ \\
\hline $\begin{array}{l}\text { Al-Hosni et al. } \\
\text { (80) }\end{array}$ & 2012 & $\mathrm{RCT}$ & 101 & Birth weight $<1000 \mathrm{~g}$ & $\begin{array}{l}\text { Lactobacillus rhamnosus } \\
\text { Bifidobacterium infantis }\end{array}$ & $5 \times 10^{8} \mathrm{CFU}$ each & $\begin{array}{l}\text { No effect on incidence of and mortality due to NEC } \\
\text { Probiotic supplemented feedings improved growth velocity }\end{array}$ \\
\hline Braga et al. (81) & 2011 & $\mathrm{RCT}$ & 231 & Birth weight $<1500 \mathrm{~g}$ & Bifidobacterium breve & $3.5-3.7 \times 10^{7} \mathrm{CFU}$ & Significant decrease in incidence of NEC (Bell stage $\geq 2$ ) \\
\hline $\begin{array}{l}\text { Samanta et al. } \\
\text { (82) }\end{array}$ & 2009 & $\mathrm{RCT}$ & 186 & $\begin{array}{l}<32 \text { weeks Gestational age } \\
\text { Birth weight }<1500 \mathrm{~g}\end{array}$ & $\begin{array}{l}\text { Bifidobacterium bifidum } \\
\text { Bifidobacterium infantis } \\
\text { Bifidobacterium longum } \\
\text { Lactobacillus acidophilus }\end{array}$ & $2.5 \times 10^{9} \mathrm{CFU}$ each & $\begin{array}{l}\text { Significant decrease in incidence of and death due to NEC } \\
\text { Decreased feeding intolerance in infants receiving probiotic therapy }\end{array}$ \\
\hline Lin et al. (83) & 2008 & $\mathrm{RCT}$ & 234 & $\begin{array}{l}<34 \text { weeks Gestational age } \\
\text { Birth weight }<1500 \mathrm{~g}\end{array}$ & $\begin{array}{l}\text { Bifidobacterium bifidum } \\
\text { Lactobacillus acidophilus }\end{array}$ & $1 \times 10^{9} \mathrm{CFU}$ each & Significant decrease in incidence of NEC or death \\
\hline Lin et al. (84) & 2005 & $\mathrm{RCT}$ & 367 & Birth weight $<1500 \mathrm{~g}$ & $\begin{array}{l}\text { Bifidobacterium infantum } \\
\text { Lactobacillus acidophilus }\end{array}$ & $1 \times 10^{9} \mathrm{CFU}$ each & Significant decrease in incidence of NEC or death \\
\hline $\begin{array}{l}\text { Bin Nun et al. } \\
\text { (85) }\end{array}$ & 2005 & $\mathrm{RCT}$ & 145 & Birth weight $<1500 \mathrm{~g}$ & $\begin{array}{l}\text { Bifidobacterium bifidus } \\
\text { Bifidobacterium infantum } \\
\text { Streptococcus thermophilus }\end{array}$ & $1 \times 10^{9} \mathrm{CFU}$ each & Significant decrease in incidence and severity of NEC \\
\hline
\end{tabular}


they noted that following cessation of probiotic therapy, detection decreased to pre-intervention levels, suggesting that there is the possibility that certain probiotics may not persist permanently (87). Tobin et al. detected via qPCR the initial presence of $3 / 3$ probiotic species in $83 \%$ of premature infants who ingested probiotics after a week of treatment, but noted colonization by only one species in $75 \%$ of patients four weeks after cessation of probiotic therapy (90). Other studies on probiotic gut colonization in both preterm and full-term neonates have demonstrated lower levels of colonization (91-93) as well as transient colonization (94). These results suggest that the effectiveness of different probiotic preparations in colonizing the gut may underlie variability in clinical trial results as noted in Table 2 (89). To date, no clinical trials have correlated probiotic colonization with efficacy in the preterm neonatal population, a population thought by many to be more amenable to colonization (87) but with the advent of higher resolution techniques such as qPCR to help characterize the composition of the gut microbiome, this should be investigated further.

Proposed mechanisms of probiotic action at the level of the gut epithelium include enhanced epithelial barrier function, enhanced mucosal IgA responses, direct antagonism against pathogens, competitive exclusion of pathogens, prevention of apoptosis, production of anti-inflammatory cytokines, and down-regulation of pro-inflammatory pathways such as activation of nuclear factor $\kappa \mathrm{B}(55,64,68,95)$. The precise mode of action of probiotics is likely strain-dependent, and is difficult to assess due to the overall complexity of the microbiota and its interaction with the immune system (96). In vitro and in vivo studies have demonstrated that Lactobacillus and Bifidobacterium exert direct effects on intestinal epithelial barrier function by decreasing intestinal permeability and improving intestinal epithelial resistance (96-99). In vitro studies by Karczewski et al. with L. plantarum demonstrated a possible role for toll like receptor 2 (TLR2) as one important mediator of epithelial cell barrier integrity (100). This study also suggested that interplay between probiotic species and the gut epithelium may have an immunomodulatory effect by regulating enterocyte cytokine production $(96,100)$. Martin also suggests that consumption of probiotic species may alter the balance of Th1/Th2 equilibrium within the gut and may lead to prevention or treatment of allergies or infectious diseases (96). Smelt et al. demonstrated that short-term administration of two different lactobacillus strains ( $L$. plantarum WCFS1 and L. salivarius UCC118) to healthy adult mice induces marked changes in cellular adaptive immune responses in a strain-specific manner (101). L. plantarum was shown to increase the frequency of regulatory $\mathrm{T}$ cells while decreasing responsiveness of Th2 cells and increasing responsiveness of CD8+ T cells in the spleen and/or mesenteric lymph nodes, suggesting a role for this species in modulating Th2-mediated allergic disease and host response to viral infections that require activation of CD8+ T cells. L. salivarius also decreased responsiveness of Th2 cells but had no effect on frequency of regulatory $\mathrm{T}$ cells and demonstrated a more modest increase in CD8 $+\mathrm{T}$ cell responsiveness (101). The study also demonstrated immunomodulation by Lactococcus lactis, a non-probiotic species (101). This strain-specific immunomodulation may, in part, underlie the variability in reported effects of different probiotic species across clinical trials in humans.
Another aspect of the probiotic debate that is of paramount importance is the question of its safety as a therapy for mitigating or preventing disease. An extensive literature review of studies addressing the safety of probiotics by Hempel et al. in 2011 concluded that "there is a lack of assessment and systematic reporting of adverse events in probiotic intervention studies, and interventions are poorly documented" (102). The authors cited several case studies in both adults and pediatric populations describing fungemia $(n=33)$ and bacteremia $(n=8)$ potentially associated with probiotic administration and noted that controlled trials did not routinely monitor for infection of test subjects receiving probiotic therapy (102). Zbinden et al. recently published a case series of three VLBW neonates who developed Bifidobacterium longum bacteremia after receiving Infloran, a commonly used commercially available probiotic preparation containing Lactobacillus acidophilus and B. longum (103). Two of the three cases resulted in a transient bacteremia, the third presented as septicemia in the setting of NEC. In all three cases, the Bifidobacteria isolated from patient blood cultures and in the Infloran capsule were genetically and biochemically identical (103). Kitajima et al. reported an interesting incidental finding of cross-contamination, resulting in asymptomatic nosocomial acquisition of probiotic strains by untreated infants in a NICU. Their group reported colonization rates of 73 and $91 \%$ in their probiotic group at 2 and 6 weeks' of treatment, and colonization rates of 12 and $44 \%$ in control group infants at the same time points (91). However, it is important to mention that the analysis by Hempel et al. of probiotic administration did not show a statistically significant increased risk of adverse events such as GI illness or infection (102).

There is a strong body of evidence that provides promising evidence in favor of use of probiotics in the preterm population. A 2014 Cochrane review regarding efficacy and safety of probiotics for prevention and amelioration of NEC, acknowledges the aforementioned discrepancies between trials, citing need for improved standardized, head to head studies of type, duration, and amount of probiotic to be used, but still strongly advocates for their use (72). The authors of the review evaluated 24 eligible trials, each with notable variability regarding enrollment criteria, dose, formulation, and feeding regimens between studies. Despite the variability noted above, a meta-analysis of the trial data still demonstrated a significant reduction in the incidence and mortality of severe NEC, despite the degree of variability across studies analyzed (72). Additionally, the included trials reported no adverse events such as systemic infection with organisms found in probiotic preparations used (72). As such, the authors of the review call confidently for a change in practice based on their results. Similar results were previously described in 2010 metaanalysis by Deshpande et al. who evaluated 11 RCTs involving 2176 neonates. They reported that $6.56 \%$ of 1082 infants who did not receive probiotics developed NEC compared with $2.37 \%$ of 1094 infants who did receive probiotic supplementation and that there was a statistically significant lower relative risk $\{\mathrm{RR}: 0.35$ [95\% confidence interval (CI): 0.23-0.55] $(P<0.00001)\}$ of NEC in the probiotic group. They quoted a number needed to treat (NNT) with probiotics to prevent one case of NEC of 25 (71). No significant heterogeneity across studies was observed in their analysis of the data; however, it is important to remember that 
adjusting for heterogeneity in such meta-analyses may not be sufficient if different probiotic strains are being used. The analysis also confirmed lack of probiotic effect on incidence of late-onset sepsis in preterm neonates. In light of these results, the authors claimed that it could be considered unethical to deny probiotics from at-risk neonates and advocated for their use without any further placebo-controlled trials (71). A 2012 meta-analysis of 20 RCTs by Wang et al. echoed these results, finding that probiotic administration was associated with a significantly decreased risk of NEC and death from NEC in the VLBW preterm neonatal population, with no difference between treatment and placebo groups when evaluating for risk of sepsis (70). More recently, Janvier et al. published results of a randomized trial describing the effect of probiotic administration on incidence and severity of NEC in a single NICU since July 2011. They administered a probiotic preparation composed of four species of Bifidobacterium to 294 infants at $<32$ weeks' gestational age, and compared them to 317 infants in a control group. They observed a statistically significant reduction in incidence and severity of NEC, but no effect on incidence of nosocomial infection, once again suggesting a protective role of probiotic therapy (73).

It is important, however, that standardized large-scale trials to more thoroughly evaluate the role of probiotics in preventing NEC in the premature low birth weight population be done in an effort to solve unresolved issues mentioned above (104).

Chan et al. recently called "for more stringent regulations to hold the manufacturers of probiotics to safety standards similar to those with prescription medications so that well-designed observational studies to rigorously evaluate the safety of various strains and regimens can be conducted" (105). In USA, the FDA has published the Dietary Supplement Good Manufacturing Guidelines (http://www.fda.gov/Food/GuidanceRegulation/ CGMP/ucm110858.htm), effective June 2008, which require that dietary supplements are manufactured consistently as to their identity, purity, strength, and composition. This is to ensure that consumers (i.e., NICUs in the present context) will have access to dietary supplements that meet quality standards that are free from contamination and are accurately labeled. The rule addresses the quality of manufacturing processes for dietary supplements and the accurate listing of supplement ingredients. However, this rule is currently not enforceable to the stringent standards of prescription medications, and is dependent on the manufacturer. The fact remains that there are already NICUs around the world that are/have been using probiotics to decrease rates of NEC, with published evidence-based guidelines (74), even as the multifaceted body of scientific literature surrounding their use grows.

\section{DIRECTIONS FOR FURTHER RESEARCH}

As research surrounding the human microbiome continues to expand, we gather more information about its development and function that may ultimately assist us in a better understanding of lifelong disease processes. Because the genesis of the human microbiome is primarily influenced by factors external to the host, rather than intrinsic genetic factors, an understanding of these factors and how they can be manipulated could impact the balance between health and disease beginning at or even before birth. In time, we may be able to harness the power of this knowledge to guide newborn delivery decision making, and to target use of pre- and pro-biotic species to promote an as yet to be elucidated "healthy" gut milieu. These potential interventions could ultimately allow for prevention of and/or intervention against infectious and immune-mediated disease beginning as early as the neonatal period.

\section{REFERENCES}

1. Chen K, Pachter L. Bioinformatics for whole-genome shotgun sequencing of microbial communities. PLoS Comput Biol (2005) 1:106-12. doi:10.1371/ journal.pcbi.0010024

2. Fricke WF. The more the merrier? Reduced fecal microbiota diversity in preterm infants treated with antibiotics. J Pediatr (2014) 165:8-10. doi:10. 1016/j.jpeds.2014.03.022

3. Berrington JE, Stewart CJ, Cummings SP, Embleton ND. The neonatal bowel microbiome in health and infection. Curr Opin Infect Dis (2014) 27:236-43. doi:10.1097/QCO.0000000000000061

4. Putignani L, Del Chierico F, Petrucca A, Vernocchi P, Dallapiccola B. The human gut microbiota: a dynamic interplay with the host from birth to senescence settled during childhood. Pediatr Res (2014) 76:2-10. doi:10.1038/pr.2014.49

5. Aagaard K, Ma J, Antony KM, Ganu R, Petrosino J, Versalovic J. The placenta harbors a unique microbiome. Sci Transl Med (2014) 6:237ra65. doi:10.1126/ scitranslmed.3008599

6. Adlerberth I, Wold AE. Establishment of the gut microbiota in Western infants. Acta Paediatr (2009) 98:229-38. doi:10.1111/j.1651-2227.2008.01060.x

7. Sood R, Zehnder JL, Druzin ML, Brown PO. Gene expression patterns in human placenta. Proc Natl Acad Sci U S A (2006) 103:5478-83. doi:10.1073/ pnas.0508035103

8. Stout MJ, Conlon B, Landeau M, Lee I, Bower C, Zhao Q, et al. Identification of intracellular bacteria in the basal plate of the human placenta in term and preterm gestations. Am J Obstet Gynecol (2013) 208:.e1-7. doi:10.1016/j.ajog.2013.01.018

9. Madan JC, Salari RC, Saxena D, Davidson L, O'Toole GA, Moore JH, et al. Gut microbial colonisation in premature neonates predicts neonatal sepsis. Arch Dis child Fetal Neonatal Ed (2012) 97:F456-62. doi:10.1136/fetalneonatal-2011301373

10. Ardissone AN, de la Cruz DM, Davis-Richardson AG, Rechcigl KT, Li N, Drew JC, et al. Meconium microbiome analysis identifies bacteria correlated with premature birth. PLoS One (2014) 9:e90784. doi:10.1371/journal.pone. 0090784

11. Chassard C, de Wouters T, Lacroix C. Probiotics tailored to the infant: a window of opportunity. Curr Opin Biotechnol (2014) 26:141-7. doi:10.1016/j.copbio. 2013.12.012

12. Maynard CL, Elson CO, Hatton RD, Weaver CT. Reciprocal interactions of the intestinal microbiota and immune system. Nature (2012) 489:231-41. doi:10.1038/nature11551

13. Eckburg PB, Bik EM, Bernstein CN, Purdom E, Dethlefsen L, Sargent M, et al. Diversity of the human intestinal microbial flora. Science (2005) 308:1635-8. doi:10.1126/science.1110591

14. Madan JC, Farzan SF, Hibberd PL, Karagas MR. Normal neonatal microbiome variation in relation to environmental factors, infection and allergy. Curr Opin Pediatr (2012) 24:753-9. doi:10.1097/MOP.0b013e32835alac8

15. Di Mauro A, Neu J, Riezzo G, Raimondi F, Martinelli D, Francavilla R, et al. Gastrointestinal function development and microbiota. Ital J Pediatr (2013) 39:15. doi:10.1186/1824-7288-39- 15

16. Torrazza RM, Neu J. The altered gut microbiome and necrotizing enterocolitis. Clin Perinatol (2013) 40:93-108. doi:10.1016/j.clp.2012.12.009

17. Scholtens PA, Oozeer R, Martin R, Amor KB, Knol J. The early settlers: intestinal microbiology in early life. Annu Rev Food Sci Technol (2012) 3:425-47. doi:10.1146/annurev-food-022811-101120

18. Biasucci G, Rubini M, Riboni S, Morelli L, Bessi E, Retetangos C. Mode of delivery affects the bacterial community in the newborn gut. Early Hum Dev (2010) 86(Suppl 1):13-5. doi:10.1016/j.earlhumdev.2010.01.004

19. Jakobsson HE, Abrahamsson TR, Jenmalm MC, Harris K, Quince C, Jernberg $\mathrm{C}$, et al. Decreased gut microbiota diversity, delayed Bacteroidetes colonisation and reduced Th1 responses in infants delivered by caesarean section. Gut (2014) 63:559-66. doi:10.1136/gutjnl-2012-303249 
20. Salminen S, Gibson GR, McCartney AL, Isolauri E. Influence of mode of delivery on gut microbiota composition in seven year old children. Gut (2004) 53:1388-9. doi:10.1136/gut.2004.041640

21. Palmer C, Bik EM, DiGiulio DB, Relman DA, Brown PO. Development of the human infant intestinal microbiota. PLoS Biol (2007) 5:e177. doi:10.1371/ journal.pbio.0050177

22. Turroni F, Peano C, Pass DA, Foroni E, Severgnini M, Claesson MJ, et al. Diversity of bifidobacteria within the infant gut microbiota. PLoS One (2012) 7:e36957. doi:10.1371/journal.pone.0036957

23. Penders J, Thijs C, Vink C, Stelma FF, Snijders B, Kummeling I, et al. Factors influencing the composition of the intestinal microbiota in early infancy. Pediatrics (2006) 118:511-21. doi:10.1542/peds.2005-2824

24. Eggesbo M, Moen B, Peddada S, Baird D, Rugtveit J, Midtvedt T, et al. Development of gut microbiota in infants not exposed to medical interventions. APMIS (2011) 119:17-35. doi:10.1111/j.1600-0463.2010.02688.x

25. Groer MW, Luciano AA, Dishaw LJ, Ashmeade TL, Miller E, Gilbert JA. Development of the preterm infant gut microbiome: a research priority. Microbiome (2014) 2:38. doi:10.1186/2049-2618-2-38

26. Yatsunenko T, Rey FE, Manary MJ, Trehan I, Dominguez-Bello MG, Contreras $\mathrm{M}$, et al. Human gut microbiome viewed across age and geography. Nature (2012) 486:222-7. doi:10.1038/nature11053

27. Jain N, Walker WA. Diet and host-microbial crosstalk in postnatal intestinal immune homeostasis. Nat Rev Gastroenterol Hepatol (2014) 12(1):14-25. doi:10.1038/nrgastro.2014.153

28. Di Gioia D, Aloisio I, Mazzola G, Biavati B. Bifidobacteria: their impact on gut microbiota composition and their applications as probiotics in infants. Appl Microbiol Biotechnol (2014) 98:563-77. doi:10.1007/s00253-013-5405-9

29. Berrington JE, Stewart CJ, Embleton ND, Cummings SP. Gut microbiota in preterm infants: assessment and relevance to health and disease. Arch Dis Child Fetal Neonatal Ed (2013) 98:F286-90. doi:10.1136/archdischild-2012-302134

30. Dai D, Walker WA. Protective nutrients and bacterial colonization in the immature human gut. Adv Pediatr (1999) 46:353-82.

31. Oozeer R, van Limpt K, Ludwig T, Ben Amor K, Martin R, Wind RD, et al. Intestinal microbiology in early life: specific prebiotics can have similar functionalities as human-milk oligosaccharides. Am J Clin Nutr (2013) 98:561s-71s. doi:10.3945/ajcn.112.038893

32. Musilova S, Rada V, Vlkova E, Bunesova V. Beneficial effects of human milk oligosaccharides on gut microbiota. Benef Microbes (2014) 5:273-83. doi:10.3920/BM2013.0080

33. Solís G, de los Reyes-Gavilan CG, Fernández N, Margolles A, Gueimonde M. Establishment and development of lactic acid bacteria and bifidobacteria microbiota in breast-milk and the infant gut. Anaerobe (2010) 16:307-10. doi:10.1016/j.anaerobe.2010.02.004

34. Civardi E, Garofoli F, Tzialla C, Paolillo P, Bollani L, Stronati M. Microorganisms in human milk: lights and shadows. J Matern Fetal Neonatal Med (2013) 26(Suppl 2):30-4. doi:10.3109/14767058.2013.829693

35. Latuga MS, Stuebe A, Seed PC. A review of the source and function of microbiota in breast milk. Semin Reprod Med (2014) 32:68-73. doi:10.1055/s-00331361824

36. Donnet-Hughes A, Perez PF, Dore J, Leclerc M, Levenez F, Benyacoub J, et al. Potential role of the intestinal microbiota of the mother in neonatal immune education. Proc Nutr Soc (2010) 69:407-15. doi:10.1017/S0029665110001898

37. Power SE, O'Toole PW, Stanton C, Ross RP, Fitzgerald GF. Intestinal microbiota, diet and health. Br J Nutr (2014) 111:387-402. doi:10.1017/ S0007114513002560

38. Gomez-Llorente C, Plaza-Diaz J, Aguilera M, Munoz-Quezada S, BermudezBrito M, Peso-Echarri P, et al. Three main factors define changes in fecal microbiota associated with feeding modality in infants. J Pediatr Gastroenterol Nutr (2013) 57:461-6. doi:10.1097/MPG.0b013e31829d519a

39. Jost T, Lacroix C, Braegger CP, Chassard C. New insights in gut microbiota establishment in healthy breast fed neonates. PLoS One (2012) 7:e44595. doi:10.1371/journal.pone.0044595

40. Piacentini G, Peroni D, Bessi E, Morelli L. Molecular characterization of intestinal microbiota in infants fed with soymilk. J Pediatr Gastroenterol Nutr (2010) 51:71-6. doi:10.1097/MPG.0b013e3181dc8b02

41. Guaraldi F, Salvatori G. Effect of breast and formula feeding on gut microbiota shaping in newborns. Front Cell Infect Microbiol (2012) 2:94. doi:10. 3389/fcimb.2012.00094
42. Mackie RI, Sghir A, Gaskins HR. Developmental microbial ecology of the neonatal gastrointestinal tract. Am J Clin Nutr (1999) 69:1035s-45s.

43. Hascoet JM, Hubert C, Rochat F, Legagneur H, Gaga S, Emady-Azar S, et al. Effect of formula composition on the development of infant gut microbiota. J Pediatr Gastroenterol Nutr (2011) 52:756-62. doi:10.1097/MPG. 0b013e3182105850

44. Manco M. Gut microbiota and developmental programming of the brain: from evidence in behavioral endophenotypes to novel perspective in obesity. Front Cell Infect Microbiol (2012) 2:109. doi:10.3389/fcimb.2012.00109

45. Hochberg Z, Feil R, Constancia M, Fraga M, Junien C, Carel JC, et al. Child health, developmental plasticity, and epigenetic programming. Endocr Rev (2011) 32:159-224. doi:10.1210/er.2009-0039

46. Kalliomaki M, Collado MC, Salminen S, Isolauri E. Early differences in fecal microbiota composition in children may predict overweight. Am J Clin Nutr (2008) 87:534-8.

47. Ley RE, Backhed F, Turnbaugh P, Lozupone CA, Knight RD, Gordon JI. Obesity alters gut microbial ecology. Proc Natl Acad Sci U S A (2005) 102:11070-5. doi:10.1073/pnas.0504978102

48. Mischke M, Plosch T. More than just a gut instinct-the potential interplay between a baby's nutrition, its gut microbiome, and the epigenome. Am J Physiol (2013) 304:R1065-9. doi:10.1152/ajpregu.00551.2012

49. Luoto R, Kalliomaki M, Laitinen K, Delzenne NM, Cani PD, Salminen S, et al. Initial dietary and microbiological environments deviate in normal-weight compared to overweight children at 10 years of age. J Pediatr Gastroenterol Nutr (2011) 52:90-5. doi:10.1097/MPG.0b013e3181f3457f

50. Gupta RW, Tran L, Norori J, Ferris MJ, Eren AM, Taylor CM, et al. Histamine2 receptor blockers alter the fecal microbiota in premature infants. J Pediatr Gastroenterol Nutr (2013) 56:397-400. doi:10.1097/MPG.0b013e318282a8c2

51. Stewart CJ, Marrs EC, Nelson A, Lanyon C, Perry JD, Embleton ND, et al. Development of the preterm gut microbiome in twins at risk of necrotising enterocolitis and sepsis. PLoS One (2013) 8:e73465. doi:10.1371/journal.pone.0073465

52. Arboleya S, Binetti A, Salazar N, Fernandez N, Solis G, Hernandez-Barranco A, et al. Establishment and development of intestinal microbiota in preterm neonates. FEMS Microbiol Ecol (2012) 79:763-72. doi:10.1111/j.1574-6941. 2011.01261.x

53. Butel MJ, Suau A, Campeotto F, Magne F, Aires J, Ferraris L, et al. Conditions of bifidobacterial colonization in preterm infants: a prospective analysis. J Pediatr Gastroenterol Nutr (2007) 44:577-82. doi:10.1097/MPG.0b013e3180406b20

54. La Rosa PS, Warner BB, Zhou Y, Weinstock GM, Sodergren E, Hall-Moore $\mathrm{CM}$, et al. Patterned progression of bacterial populations in the premature infant gut. Proc Natl Acad Sci U S A (2014) 111:12522-7. doi:10.1073/pnas. 1409497111

55. Panigrahi P. Probiotics and prebiotics in neonatal necrotizing enterocolitis: new opportunities for translational research. Pathophysiology (2014) 21:35-46. doi:10.1016/j.pathophys.2013.11.016

56. Fanaroff AA, Korones SB, Wright LL, Verter J, Poland RL, Bauer CR, et al. Incidence, presenting features, risk factors and significance of late onset septicemia in very low birth weight infants. The National Institute of Child Health and Human Development Neonatal Research Network. Pediatr Infect Dis J (1998) 17:593-8. doi:10.1097/00006454-199807000-00004

57. Mai V, Torrazza RM, Ukhanova M, Wang X, Sun Y, Li N, et al. Distortions in development of intestinal microbiota associated with late onset sepsis in preterm infants. PLoS One (2013) 8:e52876. doi:10.1371/journal.pone.0052876

58. Neu J. The microbiome and its impact on disease in the preterm patient. Cur Pediatr Rep (2013) 1:215-21. doi:10.1007/s40124-013-0031-7

59. Carlisle EM, Morowitz MJ. The intestinal microbiome and necrotizing enterocolitis. Curr Opin Pediatr (2013) 25:382-7. doi:10.1097/MOP. 0b013e3283600e91

60. Grishin A, Papillon S, Bell B, Wang J, Ford HR. The role of the intestinal microbiota in the pathogenesis of necrotizing enterocolitis. Semin Pediatr Surg (2013) 22:69-75. doi:10.1053/j.sempedsurg.2013.01.002

61. Mai V, Young CM, Ukhanova M, Wang X, Sun Y, Casella G, et al. Fecal microbiota in premature infants prior to necrotizing enterocolitis. PLoS One (2011) 6:e20647. doi:10.1371/journal.pone.0020647

62. Morrow AL, Lagomarcino AJ, Schibler KR, Taft DH, Yu Z, Wang B, et al. Early microbial and metabolomic signatures predict later onset of necrotizing enterocolitis in preterm infants. Microbiome (2013) 1:13. doi:10.1186/20492618-1-13 
63. Smith B, Bode S, Skov TH, Mirsepasi H, Greisen G, Krogfelt KA. Investigation of the early intestinal microflora in premature infants with/without necrotizing enterocolitis using two different methods. Pediatr Res (2012) 71:115-20. doi:10.1038/pr.2011.1

64. Patel RM, Denning PW. Therapeutic use of prebiotics, probiotics, and postbiotics to prevent necrotizing enterocolitis: what is the current evidence? Clin Perinatol (2013) 40:11-25. doi:10.1016/j.clp.2012.12.002

65. Indrio F, Riezzo G, Raimondi F, Bisceglia M, Cavallo L, Francavilla R. Effects of probiotic and prebiotic on gastrointestinal motility in newborns. J Physiol Pharmacol (2009) 60(Suppl 6):27-31.

66. Indrio F, Riezzo G, Raimondi F, Francavilla R, Montagna O, Valenzano ML, et al. Prebiotics improve gastric motility and gastric electrical activity in preterm newborns. J Pediatr Gastroenterol Nutr (2009) 49:258-61. doi:10.1097/MPG.0b013e3181926aec

67. Mastromarino P, Capobianco D, Campagna G, Laforgia N, Drimaco P, Dileone A, et al. Correlation between lactoferrin and beneficial microbiota in breast milk and infant's feces. Biometals (2014) 27:1077-86. doi:10.1007/s10534-0149762-3

68. Ofek Shlomai N, Deshpande G, Rao S, Patole S. Probiotics for preterm neonates: what will it take to change clinical practice? Neonatology (2014) 105:64-70. doi:10.1159/000354891

69. Mihatsch WA, Braegger CP, Decsi T, Kolacek S, Lanzinger H, Mayer B, et al. Critical systematic review of the level of evidence for routine use of probiotics for reduction of mortality and prevention of necrotizing enterocolitis and sepsis in preterm infants. Clin Nutr (2012) 31:6-15. doi:10.1016/j.clnu.2011.09.004

70. Wang Q, Dong J, Zhu Y. Probiotic supplement reduces risk of necrotizing enterocolitis and mortality in preterm very low-birth-weight infants: an updated meta-analysis of 20 randomized, controlled trials. J Pediatr Surg (2012) 47:241-8. doi:10.1016/j.jpedsurg.2011.09.064

71. Deshpande G, Rao S, Patole S, Bulsara M. Updated meta-analysis of probiotics for preventing necrotizing enterocolitis in preterm neonates. Pediatrics (2010) 125:921-30. doi:10.1542/peds.2009-1301

72. AlFaleh K, Anabrees J. Probiotics for prevention of necrotizing enterocolitis in preterm infants. Cochrane Database Syst Rev (2014) 4:CD005496. doi:10.1002/14651858.CD005496.pub4

73. Janvier A, Malo J, Barrington KJ. Cohort study of probiotics in a North American neonatal intensive care unit. J Pediatr (2014) 164:980-5. doi:10.1016/j. jpeds.2013.11.025

74. Deshpande GC, Rao SC, Keil AD, Patole SK. Evidence-based guidelines for use of probiotics in preterm neonates. BMC Med (2011) 9:92. doi:10.1186/17417015-9-92

75. Oncel MY, Sari FN, Arayici S, Guzoglu N, Erdeve O, Uras N, et al. Lactobacillus reuteri for the prevention of necrotising enterocolitis in very low birthweight infants: a randomised controlled trial. Arch Dis Child Fetal Neonatal Ed (2014) 99:F110-5. doi:10.1136/archdischild-2013-304745

76. Jacobs SE, Tobin JM, Opie GF, Donath S, Tabrizi SN, Pirotta M, et al. Probiotic effects on late-onset sepsis in very preterm infants: a randomized controlled trial. Pediatrics (2013) 132:1055-62. doi:10.1542/peds.2013-1339

77. Serce O, Benzer D, Gursoy T, Karatekin G, Ovali F. Efficacy of Saccharomyces boulardii on necrotizing enterocolitis or sepsis in very low birth weight infants: a randomised controlled trial. Early Hum Dev (2013) 89:1033-6. doi:10.1016/j.earlhumdev.2013.08.013

78. Fernandez-Carrocera LA, Solis-Herrera A, Cabanillas-Ayon M, GallardoSarmiento RB, Garcia-Perez CS, Montano-Rodriguez R, et al. Double-blind, randomised clinical assay to evaluate the efficacy of probiotics in preterm newborns weighing less than $1500 \mathrm{~g}$ in the prevention of necrotising enterocolitis. Arch Dis Child Fetal Neonatal Ed (2013) 98:F5-9. doi:10.1136/archdischild2011-300435

79. Rojas MA, Lozano JM, Rojas MX, Rodriguez VA, Rondon MA, Bastidas JA, et al. Prophylactic probiotics to prevent death and nosocomial infection in preterm infants. Pediatrics (2012) 130:e1113-20. doi:10.1542/peds.2011-3584

80. Al-Hosni M, Duenas M, Hawk M, Stewart LA, Borghese RA, Cahoon M, et al. Probiotics-supplemented feeding in extremely low-birth-weight infants. J Perinatol (2012) 32:253-9. doi:10.1038/jp.2011.51

81. Braga TD, da Silva GA, de Lira PI, de Carvalho Lima M. Efficacy of Bifidobacterium breve and Lactobacillus casei oral supplementation on necrotizing enterocolitis in very-low-birth-weight preterm infants: a double-blind, randomized, controlled trial. Am J Clin Nutr (2011) 93:81-6. doi:10.3945/ajcn. 2010.29799
82. Samanta M, Sarkar M, Ghosh P, Ghosh J, Sinha M, Chatterjee S. Prophylactic probiotics for prevention of necrotizing enterocolitis in very low birth weight newborns. J Trop Pediatr (2009) 55:128-31. doi:10.1093/tropej/ fmn091

83. Lin HC, Hsu CH, Chen HL, Chung MY, Hsu JF, Lien RI, et al. Oral probiotics prevent necrotizing enterocolitis in very low birth weight preterm infants: a multicenter, randomized, controlled trial. Pediatrics (2008) 122:693-700. doi:10.1542/peds.2007-3007

84. Lin HC, Su BH, Chen AC, Lin TW, Tsai CH, Yeh TF, et al. Oral probiotics reduce the incidence and severity of necrotizing enterocolitis in very low birth weight infants. Pediatrics (2005) 115:1-4. doi:10.1542/peds.2004-1463

85. Bin-Nun A, Bromiker R, Wilschanski M, Kaplan M, Rudensky B, Caplan $\mathrm{M}$, et al. Oral probiotics prevent necrotizing enterocolitis in very low birth weight neonates. J Pediatr (2005) 147:192-6. doi:10.1016/j.jpeds.2005. 03.054

86. de Champs C, Maroncle N, Balestrino D, Rich C, Forestier C. Persistence of colonization of intestinal mucosa by a probiotic strain, Lactobacillus casei subsp. rhamnosus Lcr35, after oral consumption. J Clin Microbiol (2003) 41:1270-3. doi:10.1128/JCM.41.3.1270-1273.2003

87. Costa GN, Marcelino-Guimaraes FC, Vilas-Boas GT, Matsuo T, Miglioranza LH. Potential fate of ingested Lactobacillus plantarum and its occurrence in human feces. Appl Environ Microbiol (2014) 80:1013-9. doi:10.1128/AEM. 02588-13

88. Parks DH, Beiko RG. Identifying biologically relevant differences between metagenomic communities. Bioinformatics (2010) 26:715-21. doi:10.1093/ bioinformatics/btq041

89. Panigrahi P, Parida S, Pradhan L, Mohapatra S, Misra P, Johnson J, et al. Longterm colonization of a Lactobacillus plantarum synbiotic preparation in the neonatal gut. J Pediatr Gastroenterol Nutr (2008) 47:45-53. doi:10.1097/MPG. 0b013e31815a5f2c

90. Tobin JM, Garland SM, Jacobs SE, Pirotta M, Tabrizi SN. Rapid assay to assess colonization patterns following in-vivo probiotic ingestion. BMC Res Notes (2013) 6:252. doi:10.1186/1756-0500-6-252

91. Kitajima H, Sumida Y, Tanaka R, Yuki N, Takayama H, Fujimura M. Early administration of Bifidobacterium breve to preterm neonates: randomised control trial. Arch Dis Child (1997) 76:F101-7. doi:10.1136/fn.76.2. F101

92. Reuman PD, Duckworth DH, Smith KL, Kagan R, Bucciarelli RL, Ayoub EM. Lack of effect of Lactobacillus on gastrointestinal bacterial colonization in premature infants. Pediatr Infect Dis (1986) 5:663-8. doi:10.1097/00006454198611000-00013

93. Agarwal R, Sharma N, Chaudhry R, Deorari A, Paul VK, Gewolb IH, et al. Effects of oral Lactobacillus GG on enteric microflora in low-birthweight neonates. J Pediatr Gastroenterol Nutr (2003) 36:397-402. doi:10.1097/ 00005176-200303000-00019

94. Bennet R, Nord CE, Zetterstrom R. Transient colonization of the gut of newborn infants by orally administered bifidobacteria and lactobacilli. Acta Paediatrica (1992) 81:784-7. doi:10.1111/j.1651-2227.1992.tb12103.x

95. Collins MD, Gibson GR. Probiotics, prebiotics, and synbiotics: approaches for modulating the microbial ecology of the gut. Am J Clin Nutr (1999) 69:1052s-7s.

96. Martin R, Nauta AJ, Ben Amor K, Knippels LM, Knol J, Garssen J. Early life: gut microbiota and immune development in infancy. Benef Microbes (2010) 1:367-82. doi:10.3920/BM2010.0027

97. Garcia-Lafuente A, Antolin M, Guarner F, Crespo E, Malagelada JR. Modulation of colonic barrier function by the composition of the commensal flora in the rat. Gut (2001) 48:503-7. doi:10.1136/gut.48.4.503

98. Madsen K, Cornish A, Soper P, McKaigney C, Jijon H, Yachimec C, et al. Probiotic bacteria enhance murine and human intestinal epithelial barrier function. Gastroenterology (2001) 121:580-91. doi:10.1053/gast.2001.27224

99. Parassol N, Freitas M, Thoreux K, Dalmasso G, Bourdet-Sicard R, Rampal P. Lactobacillus casei DN-114 001 inhibits the increase in paracellular permeability of enteropathogenic Escherichia coli-infected T84 cells. Res Microbiol (2005) 156:256-62. doi:10.1016/j.resmic.2004.09.013

100. Karczewski J, Troost FJ, Konings I, Dekker J, Kleerebezem M, Brummer RJ, et al. Regulation of human epithelial tight junction proteins by Lactobacillus plantarum in vivo and protective effects on the epithelial barrier. Am J Physiol Gastrointest Liver Physiol (2010) 298:G851-9. doi:10.1152/ajpgi. 00327.2009 
101. Smelt MJ, de Haan BJ, Bron PA, van Swam I, Meijerink M, Wells JM, et al. $L$. plantarum, L. salivarius, and L. lactis attenuate Th2 responses and increase Treg frequencies in healthy mice in a strain dependent manner. PLoS One (2012) 7:e47244. doi:10.1371/journal.pone.0047244

102. Hempel S, Newberry S, Ruelaz A, Wang Z, Miles JN, Suttorp MJ, et al. Safety of probiotics used to reduce risk and prevent or treat disease. Evid Rep Technol Assess (2011) 1-645.

103. Zbinden A, Zbinden R, Berger C, Arlettaz R. Case series of Bifidobacterium longum bacteremia in three preterm infants on probiotic therapy. Neonatology (2015) 107:56-9. doi:10.1159/000367985

104. Abrahamsson TR, Rautava S, Moore AM, Neu J, Sherman PM. The time for a confirmative necrotizing enterocolitis probiotics prevention trial in the extremely low birth weight infant in North America is now! J Pediatr (2014) 165:389-94. doi:10.1016/j.jpeds.2014.05.012

105. Chan L-N, Soltani H, Hazlet TK. Probiotics for neonates: safety for prime time questioned without regulatory changes. J Pediatr (2015) 166(2):502. doi:10.1016/j.jpeds.2014.10.041
Conflict of Interest Statement: The authors declare that the research was conducted in the absence of any commercial or financial relationships that could be construed as a potential conflict of interest.

Received: 20 October 2014; accepted: 17 February 2015; published online: 05 March 2015.

Citation: Gritz EC and Bhandari V (2015) The human neonatal gut microbiome: a brief review. Front. Pediatr. 3:17. doi: 10.3389/fped.2015.00017

This article was submitted to Neonatology, a section of the journal Frontiers in Pediatrics.

Copyright $\odot 2015$ Gritz and Bhandari. This is an open-access article distributed under the terms of the Creative Commons Attribution License (CC BY). The use, distribution or reproduction in other forums is permitted, provided the original author (s) or licensor are credited and that the original publication in this journal is cited, in accordance with accepted academic practice. No use, distribution or reproduction is permitted which does not comply with these terms. 